\title{
Analisis Sistem Ruang Bakar Boiler Jenis Fluidized Bed Combustion untuk PLTU Kapasitas 8 MW
}

\author{
Ika Yuliyani ${ }^{1}$, Maridjo² ${ }^{2}$ Muhammad Abdul $\mathbf{M}^{3}$ \\ ${ }^{1}$ Jurusan Teknik Konversi Energi, Politeknik Negeri Bandung 40012 \\ Ika.yuliyani@polban.ac.id \\ ${ }^{2}$ Jurusan Teknik Konversi Energi, Politeknik Negeri Bandung 40012 \\ mmaridjo@polban.ac.id
}

\begin{abstract}
ABSTRAK
Boiler adalah alat yang berfungsi untuk memanaskan air untuk menjadi uap bertekanan dan bertemperatur tinggi, dengan menggunakan panas dari hasil pembakaran bahan bakar pada ruang bakar. Analisa sistem ruang bakar pada boiler jenis fluidized bed combustion dilakukan dengan menghitung parameter-parameter desain sistem ruang bakar dan pengaruh perubahan jenis bahan bakar terhadap efisiensi dari desain ruang bakar. Parameter-parameter sistem ruang bakar tersebut yaitu nilai laju kalor pembangkitan uap, proses pembakaran, heat balance, fuel heat input, mass balance, furnace cross section, furnace height, dan ketebalan dinding ruang bakar. Hasil perhitungan diketahui bahwa untuk membangkitkan daya PLTU dengan kapasitas 8 MW membutuhkan kalor pembangkitan uap sebesar $6279 \mathrm{kcal} / \mathrm{kw}-\mathrm{h}$ dengan kemampuan produksi uap sebesar 9,58 $\mathrm{kg} / \mathrm{s}$ dan konsumsi bahan bakar sebesar 1,196 kg/s. Sedangkan hasil perhitungan parameter-parameter desain sistem ruang bakar diperoleh dimensi luas ruang bakar sebesar $109,871 \mathrm{~m}^{2}$, luas dinding ruang bakar $103,67 \mathrm{~m}^{2}$, luas penampang bed sebesar $8,858 \mathrm{~m}^{2}$, panjang $4,21 \mathrm{~m}$, lebar 2,105 m, tinggi $8,21 \mathrm{~m}$, dan ketebalan dinding ruang bagian luar menggunakan material blanket alumina silica fiber dengan ketebalan 1,893 cm serta bagian dalam menggunakan material fireclay brick dengan ketebalan $30,45 \mathrm{~cm}$. Berdasarkan parameter-parameter tersebut maka pengaruh perubahan jenis batu bara berpengaruh terhadap efisiensi sistem ruang bakar boiler. Untuk kecepatan fluidasi sebesar 4,293 m/s jenis bahan bakar sub bituminus mampu menghasilkan efisiensi sistem ruang bakar boiler jenis fluidized bed sebesar $85,824 \%$.
\end{abstract}

Kata kunci: Boiler, Furnace, Fluidized Bed Combustion, ruang bakar.

\section{PENDAHULUAN}

\subsection{Latar Belakang}

Salah satu komponen penting untuk membangkitkan listrik di PLTU adalah boiler. Boiler merupakan komponen yang akan mengubah air menjadi uap yang akan dilanjutkan ke proses pembangkitan listrik. Untuk dapat mengubah air menjadi uap diperlukan energi panas yang didapat dari pembakaran batubara didalam ruang bakar. Kualitas uap yang dihasilkan oleh boiler ini tentunya sangat sangat dipengaruhi oleh proses pembakaran pada sistem ruang bakar boiler tersebut. Salah satu tipe dari boiler adalah water tube boiler dengan jenis ruang bakar fluidized bed combustion.

Pembakaran dengan fluidized bed combustion memiliki kelebihan dibandingkan dengan sistem pembakaran konvensional antara lain fleksibel terhadap bahan bakar, efisiensi pembakaran yang tinggi, pembakaran fluidized bed berlangsung pada suhu yang lebih rendah berlangsung pada suhu yang lebih rendah berkisar antara $850{ }^{\circ} \mathrm{C}$ sehingga menghasilkan kadar $\mathrm{NO}_{\mathrm{x}}$ lebih sedikit dan dapat menghindari masalah pembentukan terak pada beberapa jenis batubara tertentu. Keunggulan utama pembakaran fluidized bed adalah pereduksian kadar sulfur dioksida $\left(\mathrm{SO}_{2}\right)$ yang biasanya terbentuk dari pembakaran kandungan belerang didalam batubara (Basu P. , 2015). Pereduksian kadar $\mathrm{SO}_{2}$ dilakukan dengan menambahkan batu kapur $\left(\mathrm{CaCO}_{3}\right)$ kedalam ruang bakar. Karena pentingnya peran dari ruang bakar pada suatu boiler, penelitian ini akan menganalisa sistem ruang bakar pada boiler jenis fluidized bed combustion untuk PLTU kapasitas 8 MW.

\subsection{Tujuan}

1. Mengetahui sistem ruang bakar pada boiler jenis fluidized bed combustion untuk PLTU kapasitas $8 \mathrm{MW}$.

2. Menghitung konsumsi bahan bakar, kebutuhan bahan bakar dan energi pembakaran yang dihasilkan oleh sistem ruang bakar boiler jenis fluidized bed combustion. 
3. Menganilisis sistem ruang bakar boiler jenis fluidized bed combustion dengan melihat perubahan jenis batubara terhadap konsumsi bahan bakar dan efisiensi.

\section{TINJAUAN PUSTAKA}

\subsection{Fluidized Bed Combustion}

Fluidized Bed Combustion adalah salah satu tipe system pembakaran pada boiler, dan komponen utama yang digunakan adalah bed yang berupa pasir silica. Udara ditiupkan pada partikel bed sehingga terjadi fluidasi.

Ada dua tipe utama boiler fluidized bed combustion:

1. Bubbling fluidized bed (BFB)

2. Circulating fluidized bed (CFB)

Dalam perancangan ini boiler yang digunakan adalah boiler jenis circulating fluidized bed.

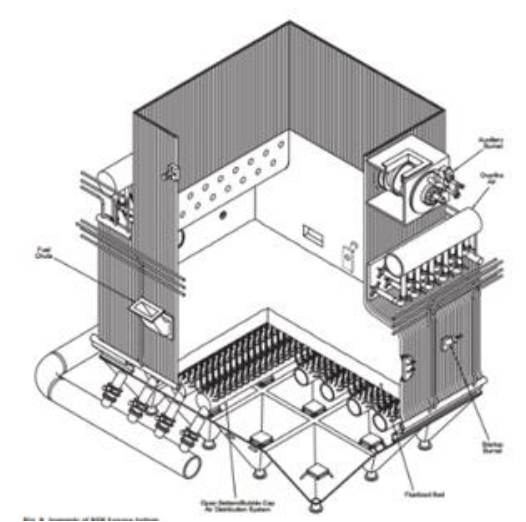

Gambar2.1 Fluidized bed combustion

(The Babcock \& Wilcox, 2005)

\subsubsection{Circulating Fluidized Bed Boiler}

Circulating fluidized bed (CFB) boiler merupakan salah satu jenis pembakaran dari fluidized bed combustion. Teknologi ini sudah sangat dikenal dalam industry pembangkitan listrik baik dari segi ekonomis maupun emisi gas buang yang dihasilkan.

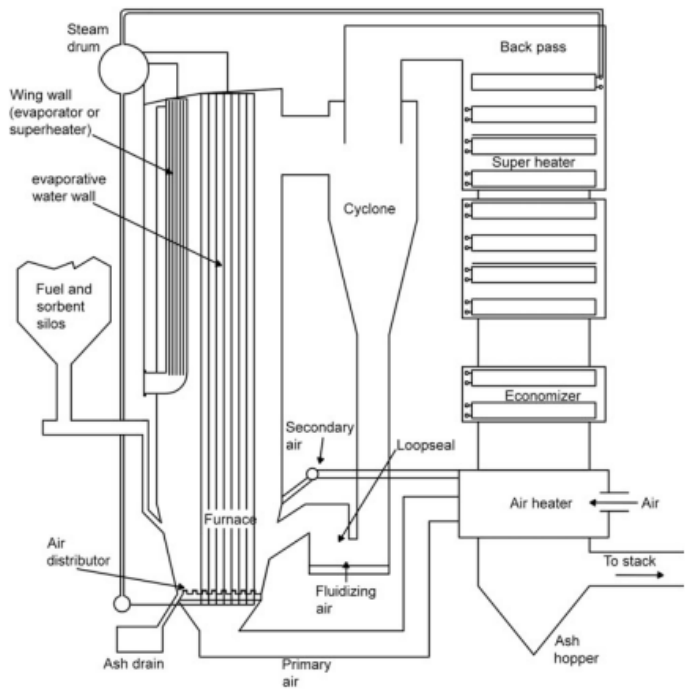

Gambar2.2 Circulating fluidized bed boiler

Boiler CFB dapat dibagi menjadi dua bagian. Bagian pertama adalah loop CFB, sedangkan untuk yang kedua adalah back-pass yang terdiri dari reheater, superheater, economizer, dan airpreheater. Back-pass dari boiler CFB mirip dengan boiler pulverizer ataupun bubbling fluidized bed. Loop CFB dari mencakup elemen berikut:

1. Ruang bakar atau riser dari unggun fast fluidized bed

2. Pemisah gas-padat (cyclone)

3. Solid recycle device (seal loop)

4. External heat exchanger (opsional)

\subsubsection{Bed Material}

Fluidized bed boiler adalah sejenis generator uap dimana bahan bakar dibakar dalam keadaan terfluidasi (Gambar 2.3). Tungku dari fluidized bed boiler mengandung massa padatan granular, umumnya dalam kisaran ukuran 0,1 sampai 0,3 mm. Padatan ini disebut bed material, partikel yang dapat digunakan adalah sebagai berikut:

- Pasir atau kerikil (untuk boiler membakar bahan bakar rendah abu)

- Batu kapur segar atau bekas (untuk boiler yang membakar batubara sulfur tinggi yang membutuhkan kontrol emisi sulfur)

- Abu dari batu bara (untuk boiler yang menembaki batubara dengan abu tinggi atau sedang yang tidak memerlukan retensi sulfur)

Kecepatan gas dicapai diantara kecepatan fluidisasi minimum dan kecepatan masuk partikel. Hal ini menjamin operasi bed yang stabil dan menghindari terbawanya partikel dalam alur gas. Pasir dalam keadaan terfluidasi dapat dilihat pada gambar berikut: 

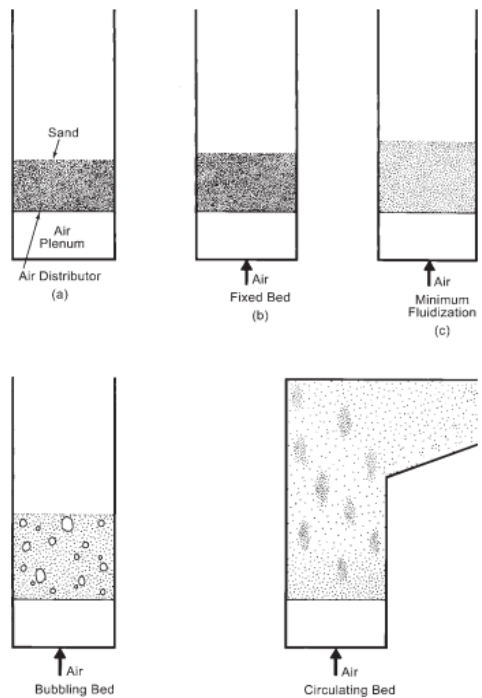

Gambar 2.3 Proses fluidasi bed material

(The Babcock \& Wilcox, 2005)

\subsubsection{Fast Fluidized Bed}

Dalam konteks penggunaannya dalam boiler CFB, fast fluidized bed dapat didefinisikan sebagai: suspensi padat-gas kecepatan tinggi dimana partikel, yang dipisahkan oleh gas fluidisasi di atas kecepatan terminal partikel, dipulihkan dan dikembalikan ke dasar tungku pada tingkat yang cukup tinggi sehingga menyebabkan tingkat pengembaliaan padatan yang akan memastikan tingkat minimum keseragaman temperatur di ruang bakar (Basu P. , 2015). Minimum fluidasi dan kecepatan terminal partikel dapat dilihat pada Tabel 2.1.

Tabel 2.1 Minimum fluidasi dan kecepatan terminal partikel
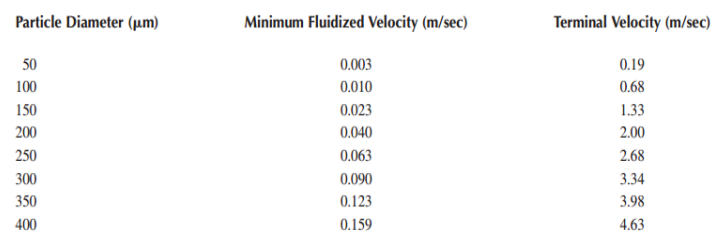

(Basu P. , 2006)

\subsection{Tahap Rancangan Ruang Bakar}

Untuk mendapatkan ukuran ruang bakar perlu diketahui parameter desain yang digunakan dalam proses perancangan sehingga proses pembakaran didalam ruang bakar menjadi optimal. Sehingga perlu dihitung laju kalor pembangkitan uap untuk PLTU kapasitas $8 \mathrm{MW}$, proses pembakaran (stoichiometric), heat balance, mass balance, fuel heat input. Dalam perancangan ruang bakar pertimbangan utama dalam penentuan ukuran dasar ruang bakar boiler CFB, yang meliputi:

\section{Furnace cross section}

Perhitungan ini dilakukan untuk mendapatkan kinerja maksimum dari proses unggun terfluidisasi yang cepat, bed harus dioperasikan dalam batas-batas kecepatan kecepatan dan sirkulasi tertentu. Dapat dihitung dengan persamaan pada buku (Basu P. , 2015) sebagai berikut:

- Kebutuhan kalor pembakaran

$$
\dot{Q}_{b b}=\dot{m}_{c} \times \mathrm{LHV}
$$

- Luas penampang bed

$$
\mathrm{A}_{\mathrm{bed}}=\frac{Q_{i}}{\text { Heat release }}
$$

- Massa jenis gas buang

$$
\rho_{\mathrm{f}}=\mathrm{n} \times \frac{P}{R_{g} \times T_{\text {furnace }}}
$$

- Kecepatan fluidasi

Untuk menghindari erosi pada ruang bakar adalah penggunaan kecepatan fluidisasi yang tidak melebihi 5 m/s (Basu P., 2006).

$$
\mathrm{V}_{\text {fluidizing }}=\frac{\dot{m}_{f g}}{\rho \mathrm{x} A_{\text {bed }}}
$$

- Luas yang dibutuhkan primary air

$$
\mathrm{A}_{\mathrm{pa}}=\frac{\dot{m}_{p a}}{\dot{m}_{\text {air }}} \times \mathrm{A}_{\text {bed }}
$$

- Lebar

$$
\mathrm{W}=\left(\frac{A_{b e d}}{2}\right)^{0,5}
$$

- Panjang

$$
\mathrm{B}=\frac{A_{b e d}}{W}
$$

\section{Furnace height}

Perhitungan ini dilakukan untuk mengetahui dimensi-dimensi dan tinggi ruang bakar yang dibutuhkan dalam perancangan ruang bakar. Nilai furnace height diketahui menggunakan pesamaan pada buku (Basu P. , 2015) sebagai berikut:

- Temperatur dinding ruang bakar

$$
\mathrm{T}_{\text {wall }}=\mathrm{T}_{\text {sat }}+25\left[{ }^{\circ} \mathrm{C}\right]
$$

- Laju kalor di evaporator

$$
\dot{Q}_{\text {eva }}=\mathrm{m}_{\text {steam }} \mathrm{x}\left(\mathrm{h}_{3}-\mathrm{h}_{2}\right)
$$

- Log mean temperature difference

$$
\mathrm{LMTD}=\frac{\Delta T_{1}-\Delta T_{2}}{\ln \left(\frac{\Delta T_{1}}{\Delta T_{2}}\right)}
$$

- Luas evaporator

$$
\mathrm{A}_{\mathrm{eva}}=\frac{\dot{Q}_{\text {eva }}}{L M T D \times U_{h}}
$$

- Rasio luas permukaan aktual dengan luas dinding proyek 


$$
\mathrm{A}_{\mathrm{x}}=\frac{\pi x \frac{D}{2}+p-D}{p}
$$

- Luas proyek yang dibutuhkan

$$
\mathrm{A}=\frac{A_{\text {eva }}}{A_{x}}
$$

- Luas roof

$$
\mathrm{A}_{\text {roof }}=\mathrm{A}_{\text {bed }}
$$

- Luas dinding ruang bakar

$$
\mathrm{A}_{\text {wall }}=\mathrm{A}-\mathrm{A}_{\text {roof }}
$$

- Opening area

$$
\mathrm{A}_{\text {unvailable }}=0,3 \times \mathrm{A}_{\text {bed }}
$$

- Luas dinding ruang bakar keseluruhan

$$
\mathrm{A}_{\text {wall(total) }}=\mathrm{A}_{\mathrm{wall}}+\mathrm{A}_{\text {unvailable }}
$$

- Tinggi ruang bakar

$$
\mathrm{L}=\frac{A_{\text {wall }(\text { total })}}{2 x(W+B)}
$$

3. Ketebalan dinding furnace

Ketebalan dinding ruang bakar ini dibutuhkan untuk menjaga agar panas pembakaran didalam ruang bakar tetap terjaga dan tidak keluar ke lingkungan. Dapat dihitung dengan persamaan pada buku (Incropera \& Dewitt, 2011) sebagai berikut:

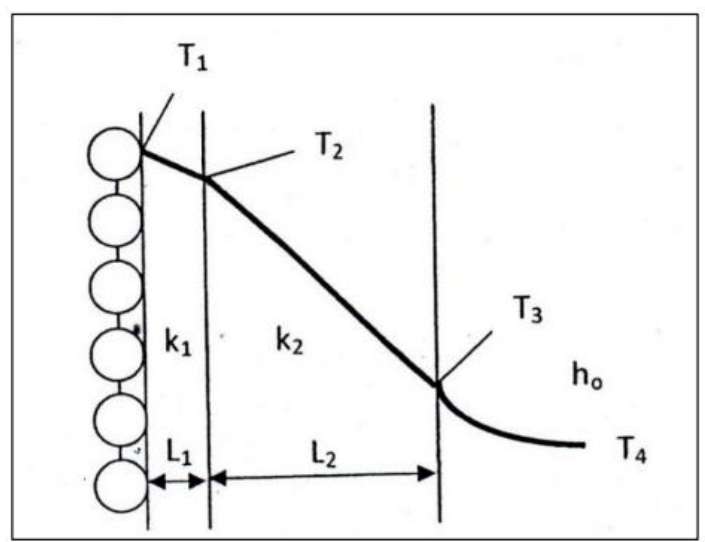

Gambar 2.4 Skematik perpindahan kalor pada dinding furnace

(Incropera \& Dewitt, 2011)

- Ketebalan dinding furnace bagian luar

$$
\mathrm{L}_{2}=\frac{K_{2} x\left(T_{2}-T_{3}\right)}{h_{0} x\left(T_{3}-T_{4}\right)}
$$

- Ketebalan dinding furnace bagian dalam

$$
\mathrm{L}_{1}=\frac{K_{1} \times\left(T_{1}-T_{2}\right)}{k_{2} \times\left(T_{2}-T_{3}\right)} \times L_{2}
$$

4. Perancangan pipa evaporator

Pipa evaporator yang digunakan dalam perancangan harus dapat menahan tekanan yang terjadi didalam pipa maupun diluar pipa untuk mencegah terjadinya ledakan akibat tekanan berlebih. Standar yang digunakan untuk merancangan pipa evaporator ini menggunakan ASME B31.3 Pressure Piping sebagai berikut:

- Ketebalan tekanan desain

$$
\mathrm{t}=\frac{P_{S} \times D}{2 x\left((S \times E \times W)+\left(P_{S} \times Y\right)\right.}
$$

- Ketebalan minimum yang dibutuhkan

$$
\mathrm{t}_{\mathrm{m}}=\mathrm{t}+\mathrm{c}
$$

- Jumlah pipa

$$
\mathrm{N}_{\mathrm{T}}=\frac{2 x(W+B)}{\text { pitch }}
$$

\section{METODOLOGI PENELITIAN}

\subsubsection{Hitungan Desain Ruang Bakar}

Untuk mendapatkan perhitungan sistem ruang bakar pada boiler terdapat beberapa tahapan yang harus dilakukan agar proses perhitungan berjalan secara sitematis dan mempermudah dalam analisa sistem. Tahapan perancangan ruang bakar pada boiler jenis fluidized bed combustion dapat dilihat pada Gambar 3.1 dibawah ini:

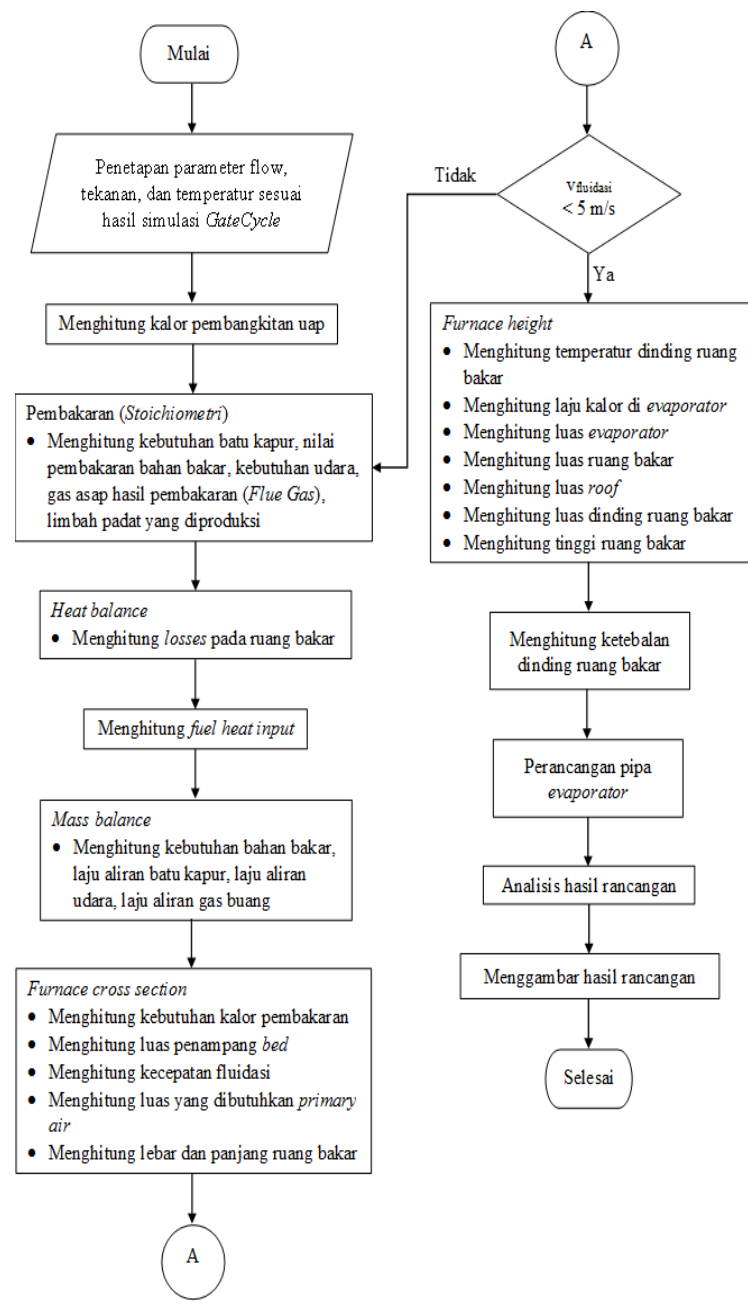

Gambar 3.1 Tahapan perancangan ruang bakar 
Rancangan diawali dengan pembuatan simulasi sistem PLTU menggunakan software GateCycle untuk didapatkan parameter yang dibutuhkan dalam proses perancangan ruang bakar jenis fluidized bed combustion. Selanjutnya dilakukan perhitungan laju kalor pembangkitan uap, pembakaran, heat balance, mass balance, kemudian dilakukan tahapan perancangan untuk mengetahui dimensi ruang bakar dengan menjaga

Data yang digunakan pada desain sistem ruang bakar jenis fluidized bed combustion didapatkan dari parameter hasil simulasi menggunakan software Gatecycle untuk dapat membangkitkan listrik sebesar 8 MW dan sumber dari literatur (Basu P. , 2015). Data yang didapatkan seperti pada Tabel 3.1.

Tabel 3.1 Data parameter boiler

\begin{tabular}{|c|c|c|c|}
\hline \multicolumn{4}{|c|}{ Boiler } \\
\hline $\begin{array}{l}\text { Temperatur gas } \\
\text { buang }\end{array}$ & $\mathrm{T}_{\mathrm{f}}$ & 190 & ${ }^{\circ} \mathrm{C}$ \\
\hline $\begin{array}{l}\text { Pereduksian kadar } \\
\mathrm{SO}_{2}\end{array}$ & $\mathrm{E}_{\mathrm{sor}}$ & 94 & $\%$ \\
\hline $\begin{array}{l}\text { Rasio } \mathrm{Ca} / \mathrm{S} \text { (kalsium } \\
\text { dan sulfur) }\end{array}$ & $\mathrm{R}$ & 3 & \\
\hline $\begin{array}{l}\text { Temperature ash } \\
\text { keluar boiler }\end{array}$ & $\mathrm{T}_{\mathrm{ash}}$ & 190 & ${ }^{\circ} \mathrm{C}$ \\
\hline Ash content & $\mathrm{X}_{\mathrm{c}}$ & 1,5 & $\%$ Carbon \\
\hline \multirow{3}{*}{ Steam } & $\mathrm{m}_{\text {steam }}$ & 9,5824 & $\mathrm{~kg} / \mathrm{s}$ \\
\hline & $\mathrm{P}_{\mathrm{s}}$ & 33 & Bar \\
\hline & $\mathrm{T}_{\mathrm{s}}$ & 408 & ${ }^{\circ} \mathrm{C}$ \\
\hline $\begin{array}{l}\text { Saturation } \\
\text { temperature }\end{array}$ & $\mathrm{T}_{\text {sat }}$ & $\begin{array}{r}239,19 \\
8 \\
\end{array}$ & ${ }^{\circ} \mathrm{C}$ \\
\hline $\begin{array}{l}\text { Feed water } \\
\text { temperature }\end{array}$ & $\mathrm{T}_{\mathrm{fw}}$ & 109,25 & ${ }^{\circ} \mathrm{C}$ \\
\hline Temperature furnace & $\begin{array}{c}\mathrm{T}_{\text {furnac }} \\
\mathrm{e}\end{array}$ & 850 & ${ }^{\circ} \mathrm{C}$ \\
\hline $\begin{array}{l}\text { Efisiensi } \\
\text { pembakaran }\end{array}$ & $\mathrm{E}_{\mathrm{c}}$ & 95 & $\%$ \\
\hline $\begin{array}{l}\text { Particle bed } \\
\text { diameter }\end{array}$ & & 200 & $\mu \mathrm{m}$ \\
\hline Tekanan bed & $\mathrm{P}$ & 1,013 & Bar \\
\hline
\end{tabular}

Batubara yang digunakan pada perancangan ini adalah jenis sub bituminus dengan spesifikasi batubara pada Tabel 3.2 sebagai berikut:

Tabel 3.2 Spesifikasi batubara sub bituminus

\begin{tabular}{|l|c|r|l|}
\hline \multicolumn{4}{|c|}{ Batubara sub-bituminus } \\
\hline $\begin{array}{l}\text { Moistures coal and } \\
\text { limestone }\end{array}$ & Mf & 11,89 & $\%$ \\
\hline Carbon & C & 60,39 & $\%$ \\
\hline Hidrogen & H & 4,24 & $\%$ \\
\hline Nitrogen & N & 1,02 & $\%$ \\
\hline
\end{tabular}

agar kecepatan fluidasi dibawah $5 \mathrm{~m} / \mathrm{s}$ untuk mencegah terjadinya erosi didalam ruang bakar (Basu P. , 2006).

\subsubsection{Simulasi Sofware GetCycle}

Hitungan desain sistem ruang bakar dimulai dengan membuat simulasi sistem PLTU kapasitas 8 MW menggunakan software GateCycle.

\begin{tabular}{|l|c|r|l|} 
Sulfur & $\mathrm{S}$ & 0,69 & $\%$ \\
\hline Oksigen & $\mathrm{O}$ & 28,2 & $\%$ \\
\hline Ash content & Ash & 5,46 & $\%$ \\
\hline Higher Heating Value & HHV & 23781,856 & $\mathrm{~kJ} / \mathrm{kg}$ \\
\hline
\end{tabular}

Spesifikasi batu kapur yang digunakan pada perancangan ini adalah sebagai berikut:

Tabel 3.3 Spesifikasi batu kapur

\begin{tabular}{|l|c|r|r|}
\hline \multicolumn{4}{|c|}{ Limestone } \\
\hline Fraksi CaCO3 & $\mathrm{X}_{\mathrm{CaCO} 3}$ & 90 & $\%$ \\
\hline Fraksi MgCO3 & $\mathrm{X}_{\mathrm{MgCO} 3}$ & 9 & $\%$ \\
\hline Fraksi inert & $\mathrm{X}_{\text {inert }}$ & 1 & $\%$ \\
\hline
\end{tabular}

\section{HASIL DAN PEMBAHASAN}

\subsection{Analisis Desain Ruang Bakar}

Setelah melakukan proses perhitungan desain sistem runag bakar boiler jenis fluidized bed combustion dengan tipe circulating fluidized bed seperti pada Tabel 4.1 sebagai berikut:

Tabel 4.1 Rancangan ruang bakar $f b c$

\begin{tabular}{|c|c|c|c|}
\hline No & Parameter & \multicolumn{2}{|c|}{ Nilai/Jenis } \\
\hline 1 & Jenis Pembakaran & \multicolumn{2}{|c|}{ FBC } \\
\hline 2 & Jenis Bahan Bakar & \multicolumn{2}{|c|}{ Sub-Bituminus Coal } \\
\hline 3 & HHV & 23.782 & $\mathrm{~kJ} / \mathrm{kg}$ \\
\hline 4 & $\begin{array}{l}\text { Luas Penampang } \\
\text { Bed }\end{array}$ & 8,858 & $\mathrm{~m}^{2}$ \\
\hline 5 & Kecepatan Fluidasi & 4,293 & $\mathrm{~m} / \mathrm{s}$ \\
\hline 6 & $\begin{array}{l}\text { Luas yang } \\
\text { dibutuhkan Primary } \\
\text { Air }\end{array}$ & 5,684 & $\mathrm{~m}^{2}$ \\
\hline 7 & Lebar & 2,105 & $\mathrm{~m}$ \\
\hline 8 & Panjang & 4,209 & $\mathrm{~m}$ \\
\hline 9 & Tinggi & 8,210 & $\mathrm{~m}$ \\
\hline 10 & Material Pipa & \multicolumn{2}{|c|}{ Carbon Steel A106 } \\
\hline 11 & Diameter Luar Pipa & 2,375 & inch \\
\hline 12 & Ketebalan Pipa & 0,154 & inch \\
\hline 13 & Pitch & 3 & inch \\
\hline
\end{tabular}




\begin{tabular}{|l|l|r|l|}
14 & Jumlah Pipa & 166 & tube \\
\hline 15 & $\begin{array}{l}\text { Luas Dinding } \\
\text { Ruang Bakar }\end{array}$ & 103,67 & $\mathrm{~m}^{2}$ \\
\hline 16 & $\begin{array}{l}\text { Ketebalan Dinding } \\
\text { Furnace Luar }\end{array}$ & 0,019 & $\mathrm{~m}$ \\
\hline 17 & $\begin{array}{l}\text { Material Dinding } \\
\text { Furnace Luar }\end{array}$ & \multicolumn{2}{|c|}{$\begin{array}{r}\text { Blanket Alumina } \\
\text { Silica Fiber }\end{array}$} \\
\hline 18 & $\begin{array}{l}\text { Ketebalan Dinding } \\
\text { Furnace Dalam }\end{array}$ & 0,305 & $\mathrm{~m}$ \\
\hline 19 & $\begin{array}{l}\text { Material Dinding } \\
\text { Furnace Dalam }\end{array}$ & Fireclay Brick \\
\hline 20 & Laju Aliran Steam & 9,58 & $\mathrm{~kg} / \mathrm{s}$ \\
\hline 21 & $\begin{array}{l}\text { Kebutuhan Bahan } \\
\text { Bakar }\end{array}$ & 1,196 & $\mathrm{~kg} / \mathrm{s}$ \\
\hline 22 & $\begin{array}{l}\text { Kebutuhan Batu } \\
\text { Kapur }\end{array}$ & 0,0537 & $\mathrm{~kg} / \mathrm{s}$ \\
\hline 23 & Laju Aliran Udara & 10,543 & $\mathrm{~kg} / \mathrm{s}$ \\
\hline 24 & Pelepasan Panas & 3,21 & $\mathrm{MW} / \mathrm{m}^{2}$ \\
\hline 25 & $\begin{array}{l}\text { Pereduksian kadar } \\
\text { SO }\end{array}$ & 94 & $\%$ \\
\hline
\end{tabular}

Agar terjadi proses fluidasi pada partikel bed dibutuhkan kecepatan fluidasi sebesar 4,293 m/s, kecepatan fluidasi hasil perancangan telah memenuhi syarat untuk terciptanya kondisi bed dalam keadaan fast fluidized bed dengan kecepatan terminal sebesar $2,00 \mathrm{~m} / \mathrm{s}$ untuk diameter partikel bed sebesar $200 \mu \mathrm{m}$ berdasarkan pada Tabel 2.4 dan kecepatan fluidasi ini dijaga agar dibawah 5 $\mathrm{m} / \mathrm{s}$ untuk mencegah terjadinya erosi pada pipa didalam ruang bakar.

Ketebalan yang digunakan pada perancangan ini telah memenuhi atau melebihi ketebalan tekanan desain sebesar 0,035 inch sesuai standar ASME B31.3 Process piping. Berdasarkan data hasil perancangan sudah memenuhi syarat mekaniknya pada tekanan 33 bar.

Ketebalan dinding ruang bakar hasil perancangan dan material yang digunakan telah memenuhi untuk temperatur lingkungan yaitu sekitar $25-$ $35^{\circ} \mathrm{C}$.

\subsubsection{Pengaruh Beban Terhadap konsumsi Bahan Bakar, Kebutuhan Udara, dan Heat Release}

Perubahan beban pada pembangkit akan mempengaruhi konsumsi bahan bakar dan kebutuhan udara pembakaran. Grafik perubahan beban dan pengaruhnya terhadap konsumsi bahan bakar dan kebutuhan udara didapatkan dari hasil simulasi menggunakan software GateCycle dan perhitungan termodinamika dapat dilihat pada Gambar 4.1.

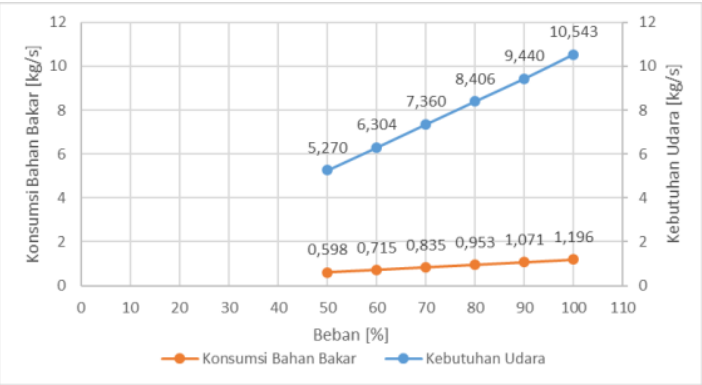

Gambar4. 1 Grafik beban vs konsumsi bahan bakar dan kebutuhan udara

Berdasarkan Gambar 4.1 yang didapatkan konsumsi bahan bakar akan semakin menurun dengan berkurangnya beban. Hal ini disebabkan seiring dengan menurunnya beban akan mengakibatkan menurunnya laju alir massa uap, maka konsumsi bahan bakar yang masuk kedalam ruang bakar boiler akan mengalami penurunan. Sehingga menurunnya jumlah energi panas yang dibutuhkan untuk mengubah sejumlah air menjadi uap yang diakibatkan jumlah laju alir massa uap menurun sehingga berdampak pada jumlah batubara yang dimasukkan kedalam ruang bakar akan cendurung menurun. Penurunan konsumsi bahan bakar batubara kedalam ruang bakar pada penurunan beban setiap 10\% berkisar antara 0,12 $\mathrm{kg} / \mathrm{s}$. Konsumsi bahan bakar pada beban $50 \%$ yaitu sebesar $0,598 \mathrm{~kg} / \mathrm{s}$ dan untuk beban $100 \%$ yaitu sebesar $1,196 \mathrm{~kg} / \mathrm{s}$. Namun perubahan beban pada pembangkit tidak akan mempengaruhi efisiensi ruang bakar. Hal ini terjadi karena nilai pembakaran atas bahan bakar (HHV) tidak berubah, sehingga perbedaan nilai tidak akan mempengaruhi efisiensi ruang bakar. Berapapun nilai beban, ruang bakar yang dirancang ini memiliki nilai efisiensi ruang bakar sebesar $85,824 \%$.

Selain mempengaruhi konsumsi bahan bakar perubahan beban juga akan mempengaruhi jumlah kebutuhan udara yang masuk untuk proses pembakaran pada saat pengoperasian boiler. Dari Gambar 4.2 dapat dilihat semakin meningkatnya beban maka kebutuhan udara untuk proses pembakaran akan ikut meningkat. Hal ini disebabkan karena konsumsi bahan bakar yang meningkat maka kebutuhan udarapun ikut meningkat untuk menjaga proses pembakaran tetap dalam keadaan pembakaran sempurna. Kebutuhan udara pada beban $50 \%$ yaitu sebesar $5,270 \mathrm{~kg} / \mathrm{s}$ dan untuk beban $100 \%$ yaitu sebesar $10,543 \mathrm{~kg} / \mathrm{s}$. Dengan nilai air fuel ratio (AFR) yang dibutuhkan selama proses pembakaran adalah sebesar 8,82: 1 .

Selain mempengaruhi konsumsi bahan bakar dan kebutuhan udara pembakaran perubahan beban juga akan mempengaruhi nilai heat release. Pada analisis ini ukuran ruang bakar dibuat konstan. 
Grafik perubahan beban dan pengaruhnya terhadap heat release dapat dilihat pada Gambar 4.2 sebagai berikut:

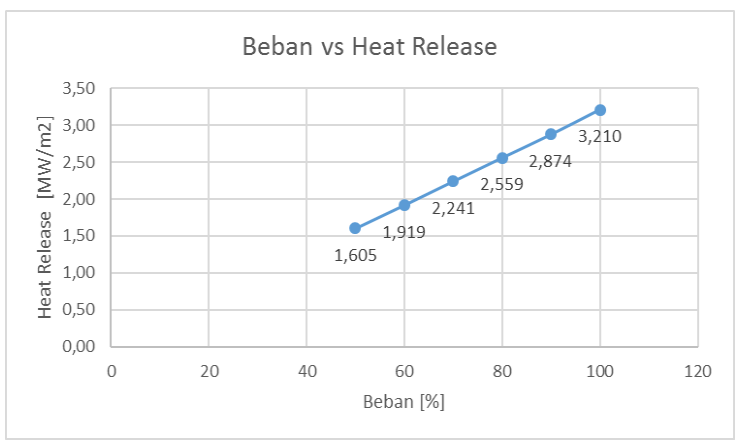

Gambar4.2 Grafik beban vs heat release

Peningkatan beban pada pembangkit akan menyebabkan nilai heat release akan semakin meningkat sesuai dengan yang ditunjukkan pada Gambar 4.2. Dengan naiknya beban maka kebutuhan uap yang digunakan untuk memutar turbin akan semakin banyak sehingga jumlah batubara yang dimasukkan kedalam ruang bakar akan semakin banyak. Dengan meningkatnya jumlah batubara yang dimasukkan kedalam ruang bakar maka pelepasan kalor perluas penampang ruang bakar akan semakin meningkat. Sesuai dengan persamaan matematis $\mathrm{A}_{\mathrm{bed}}=\frac{Q_{i}}{\text { Heat release }}$, bahwa nilai heat release berbanding lurus dengan jumlah kalor yang dimasukkan kedalam ruang bakar dan berbanding terbalik dengan luas penampang bed. Sedangkan dimensi ruang bakar dirancang agar tetap konstan.

\subsubsection{Pengaruh Jenis Batubara Terhadap Konsumsi Bahan Bakar, Efisiensi, dan Kandungan $\mathrm{SO}_{2}$ pada Ruang Bakar}

Perubahan jenis batubara dilakukan dalam kapasitas yang sama yaitu 8 MW dengan jenis batubara yang digunakan pada analisis ini yaitu lignit, sub bituminus, dan bituminus. Data pada Tabel 4.2 menunjukan jenis batubara dan perbandingan beberapa parameter yang didapatkan.

Tabel 4.2 Data jenis batubara

\begin{tabular}{|c|l|c|c|c|}
\hline No & $\begin{array}{l}\text { Jenis } \\
\text { Batubara }\end{array}$ & $\begin{array}{c}\text { HHV } \\
{[\mathbf{k J} / \mathbf{k g}]}\end{array}$ & $\begin{array}{c}\mathbf{m b b} \\
{[\mathbf{k g} / \mathbf{s}]}\end{array}$ & $\begin{array}{c}\text { Efisiensi } \\
{[\%]}\end{array}$ \\
\hline 1 & Lignit & 16975 & 1,798 & 79,938 \\
\hline 2 & $\begin{array}{l}\text { Sub } \\
\text { Bituminus }\end{array}$ & 23782 & 1,196 & 85,824 \\
\hline 3 & Bituminus & 29100 & 0,948 & 88,506 \\
\hline
\end{tabular}

Dari Tabel 4.2 tersebut dapat dibuat grafik jenis batubara dan pengaruhnya terhadap konsumsi bahan bakar dan efisiensi seperti pada Gambar 4.3.

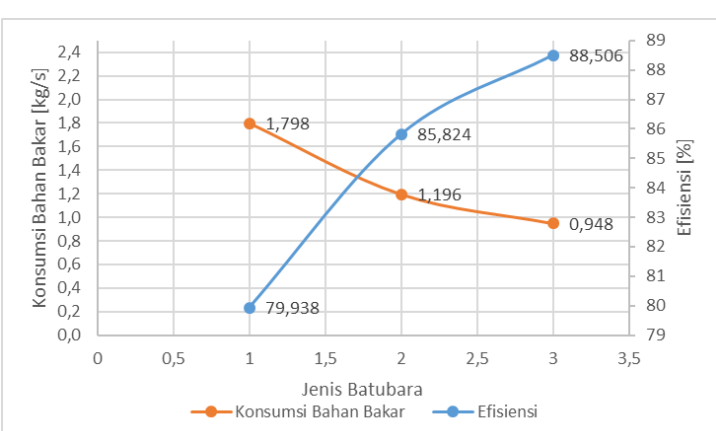

Gambar 4.3 Grafik jenis batubara vs konsumsi bahan bakar dan efisiensi

Berdasarkan Gambar 4.5 didapatkan perubahan jenis batubara berbanding terbalik dengan nilai konsumsi bahan bakar. Nilai konsumsi bahan bakar akan semakin menurun dengan jenis batubara yang semakin baik. Ini menandakan pembakaran batubara didalam ruang bakar semakin baik. Hal ini disebabkan jenis batubara yang semakin baik akan memiliki nilai kalor pembakaran atas (HHV) yang semakin tinggi maka konsumsi bahan bakar yang dibutuhkan untuk mengubah air menjadi uap menjadi lebih sedikit. Namun harga jenis batubara yang lebih baik cenderung lebih mahal sehingga perlu menjadi bahan pertimbangan juga. Jumlah konsumsi bahan bakar yang dibutuhkan untuk kapasitas pembangkit $8 \mathrm{MW}$ untuk jenis batubara lignit yaitu sebesar $1,798 \mathrm{~kg} / \mathrm{s}$, sub bituminus yaitu sebesar $1,196 \mathrm{~kg} / \mathrm{s}$, dan bituminus yaitu sebesar $0,948 \mathrm{~kg} / \mathrm{s}$.

Selain mempengaruhi konsumsi bahan bakar perubahan jenis batubara juga akan mempengaruhi niai efisiensi ruang bakar. Dari Gambar 4.5 dapat dilihat semakin bagus batubara yang digunakan maka efisiensi yang didapatkan akan semakin tinggi. Hal ini disebabkan nilai kalor pembakaran atas (HHV) yang semakin tinggi akan menyebabkan proses pembakaran didalam ruang bakar akan menjadi lebih baik sehingga losses yang terjadi didalam ruang bakar akan semakin menurun dan nilai efisiensi pun akan semakin tinggi. Nilai efisiensi yang didapatkan untuk jenis batubara lignit yaitu sebesar $79,938 \%$, sub bituminus yaitu sebesar $85,824 \%$, dan bituminus yaitu sebesar $88,506 \%$.

Batubara yang digunakan untuk mengetahui kadar $\mathrm{SO}_{2}$ yang dihasilkan pada ruang bakar adalah jenis sub bituminus dengan kandungan sulfur sebesar $0,69 \%$. Grafik rasio $\mathrm{Ca} / \mathrm{S}$ terhadap kadar $\mathrm{SO}_{2}$ yang dihasilkan pada ruang bakar dan efisiensi dapat dilihat pada Gambar 4.4 


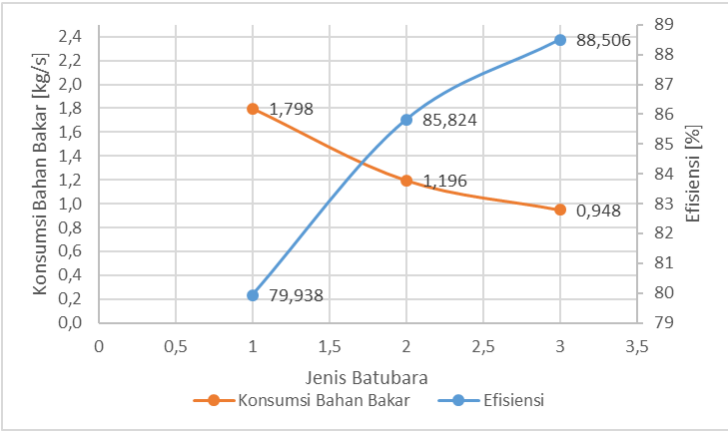

Gambar 4.4 Grafik rasio $\mathrm{Ca} / \mathrm{S}$ vs efisiensi dan kadar $\mathrm{SO}_{2}$

Berdasarkan Gambar 4.4 didapatkan nilai kandungan $\mathrm{SO}_{2}$ berbanding terbalik dengan rasio $\mathrm{Ca} / \mathrm{S}$. Nilai kandungan $\mathrm{SO}_{2}$ cenderung menurun saat rasio $\mathrm{Ca} / \mathrm{S}$ semakin meningkat. Ini menandakan pereduksian kadar $\mathrm{SO}_{2}$ didalam ruang bakar semakin baik. Hal ini dipengaruhi oleh rasio $\mathrm{Ca} / \mathrm{S}$ yang semakin meningkat dimasukan kedalam ruang bakar akan mempengaruhi jumlah batu kapur yang dimasukan kedalam ruang bakar akan semakin banyak. Batu kapur didalam ruang bakar ini akan mengalami proses kalsinasi didalam ruang bakar menjadi $\mathrm{CaO}$ dan akan mengikat kadar $\mathrm{SO}_{2}$ didalam ruang bakar. Sehingga pengikatan kadar $\mathrm{SO}_{2}$ didalam ruang bakar menjadi lebih optimal. Temperatur optimal untuk pereduksian kadar $\mathrm{SO}_{2}$ didalam ruang bakar pada temperatur $850^{\circ} \mathrm{C}$.

Selain mempengaruhi nilai kandungan $\mathrm{SO}_{2}$ didalam ruang bakar rasio $\mathrm{Ca} / \mathrm{S}$ akan mempengaruhi niai efisiensi. Berdarkan Gambar 4.4 didapatkan nilai efisiensi berbanding terbalik dengan rasio $\mathrm{Ca} / \mathrm{s}$. Nilai efisiensi akan semakin turun dengan meningkatnya rasio $\mathrm{Ca} / \mathrm{S}$. Ini menandakan efisiensi menjadi lebih buruk. Hal ini dipengaruhi oleh rasio $\mathrm{Ca} / \mathrm{S}$ akan mempengaruhi losses yang terjadi pada ruang bakar menjadi lebih besar seperti losses akibat moisture yang terkandung pada batu kapur, proses kalsinasi batu kapur menjadi $\mathrm{CaO}$ dan $\mathrm{CO}_{2}$, proses sulfation sulfur dioksida yaitu pengikatan kadar $\mathrm{SO}_{2}$ didalam ruang bakar, heat in dry flue gas yang merupakan gas buang kering dan uap air didalam gas buang. Sehingga menyebabkan nilai efisiensi menjadi lebih kecil.

\section{SIMPULAN}

Berdasarkan analisa desain sistem ruang bakar pada boiler jenis fluidized bed combustion yang telah dilakukan, didapatkan simpulan sebagai berikut:

1. Setelah melakukan proses perhitungan rancangan ruang bakar, didapatkan data hasil rancangan seperti pada Tabel 3.1.

2. Penurunan konsumsi bahan bakar batubara kedalam ruang bakar pada penurunan beban pembakit listrik setiap $10 \%$ berkisar antara $0,12 \mathrm{~kg} / \mathrm{s}$. Konsumsi bahan bakar persatuan waktu pada perancangan dengan kapasitas 8 MW sebesar $1,196 \mathrm{~kg} / \mathrm{s}$ dengan nilai air fuel ratio (AFR) yang dibutuhkan selama proses pembakaran adalah sebesar $8,82: 1$. Pelepasan kalor perluas penampang yaitu $3,21 \mathrm{MW} / \mathrm{m}^{2}$.

3. Perubahan jenis batubara yang digunakan semakin baik untuk membangkitkan listrik dengan kapasitas 8 MW akan menurunkan jumlah konsumsi bahan bakar yang dibutuhkan, dan menaikkan efisiensi pada sistem ruang bakar. Jenis batubara yang digunakan pada rancangan adalah jenis sub bituminus dengan konsumsi bahan bakar yang dibutuhkan sebesar $1,196 \mathrm{~kg} / \mathrm{s}$ dengan efisiensi sebesar $85,824 \%$.

\section{REFERENSI}

ASME. (2015). Process Piping. New York: The American Society of Mechanical Engineers.

Basu, P. (2006). Combustion and Gasification in Fluidized Beds. Francis: CRC Press.

Basu, P. (2015). Circulating Fluidized Bed Boilers. New York: Springer.

Basu, P., \& Nag, P. K. (1996). Heat Transfer to Wall of a Circulating Fluidized Bed Furnace. Chemical Engineering Science, 1-26.

Basu, P., Kefa, C., \& Jestin, L. (2000). Boilers and Burners Design and Theory. New York: Springer.

Black, \& Veatch. (1996). Power Plant Engineering. New York: Springer.

Cengel, Y. A., \& Boles, M. A. (2006). Thermodinamics: An Engineering Approach. McGraw-Hill.

El-Wakil, M. M. (1985). Powerplant Technology. Singapore: McGraw-Hill.

Incropera, F. P., \& Dewitt, D. P. (2011). Fundamentals of Heat and Mass Transfer Seventh Edition. United States of America: John Wiley \& Sons.

Kishore, N. S., Rao, T. V., \& Kumar, M. L. (2017). Furnace Design of 210 MW Circulating Fluidized Bed Boiler-Numerical Investigation. International Journal of Mechanical Engineering and Technology (IJMET), 442-455.

Rayaprolu, K. (2009). Boilers for Power and Process. USA: CRC Press.

Shi, L., Liu, G., Higgins, B. S., \& Benson, L. (2011). Computational modeling of furnace sorbent injection for $\mathrm{SO} 2$ removal from coal-fired utility boiler. Fuel Processing Technology, 372-378.

The Babcock \& Wilcox, C. (2005). Steam Its Generation and Use. Ohio: The Babcock \& Wilcox Company. 